\section{Archives of Allergy \\ and Immunology}

Int Arch Allergy Immunol 2021;182:1046-1057

DOI: $10.1159 / 000516810$
Received: February 23, 2021

Accepted: April 23, 2021

Published online: June 18, 2021

\title{
Upregulation of Basonuclin 1 Is Associated with p63-Involved Epithelial Barrier Impairment and Type-2 Helper T-cell Inflammation in Chronic Rhinosinusitis with Nasal Polyps
}

\author{
Yunbo Gao ${ }^{a, b}, c$ Jingyun $\mathrm{Li}^{\mathrm{a}}$, b Jian Jiao ${ }^{\mathrm{a}, \mathrm{b}}$ Ying $\mathrm{Li}^{\mathrm{a}}{ }^{\mathrm{a}} \mathrm{b}$ Chengshuo Wang ${ }^{\mathrm{a}, \mathrm{b}}$ \\ Yuan Zhang ${ }^{a, b}, c$ Luo Zhang ${ }^{a, b}, c$ \\ aDepartment of Otolaryngology Head and Neck Surgery, Beijing TongRen Hospital, Capital Medical University, \\ Beijing, China; ${ }^{b}$ Beijing Institute of Otolaryngology, Beijing Key Laboratory of Nasal Diseases, Beijing, China; \\ 'Department of Allergy, Beijing TongRen Hospital, Capital Medical University, Beijing, China
}

\section{Keywords}

Basonuclin1 $\cdot$ p63 . Chronic rhinosinusitis with nasal polyps - Epithelial barrier defects - Type-2 helper T-cell inflammation

\begin{abstract}
Background: Tumor protein p63 has been shown to be important for epithelial dysfunction, including epithelial barrier defects and mucosal inflammation, in the development of chronic rhinosinusitis with nasal polyps (CRSwNP). Basonuclin1 (BNC1), an epithelial-specific transcriptional factor, is a direct downstream target of p63 and thus might be involved in the pathogenesis of CRSwNP. Objective: We sought to investigate whether BNC1 was associated with p63-mediated epithelial barrier defects and nasal mucosal inflammation in CRSwNP. Methods: Nasal tissue biopsies were obtained from 91 patients to CRSwNP, 49 chronic rhinosinusitis without nasal polyps (CRSsNP) patients, and 28 control subjects. Immunohistochemistry and immunofluorescence staining were used to determine the distribution of BNC1 in tissues and localization in cells, respectively. Quantitative PCR was performed to detect the expression levels of BNC1, TP63, epithelial barrier proteins, and type-2 helper T-cell inflammationrelated genes. Results: BNC1 mRNA expression was signifi-
\end{abstract}

cantly elevated in the tissues in CRSwNP patients compared with CRSsNP (1.96-fold, $p=0.0003$ ) and control groups (2.40fold, $p<0.0001)$. BNC1 staining was strongly positive in the nasal epithelium and co-localized with p63-positive epithelial cells. The expression of BNC1 mRNA was strongly correlated with TP63 mRNA level both in tissue biopsies $(r=0.78$, $p<0.0001)$ and epithelial scrapings $(r=0.97, p<0.0001)$. $B N C 1$ expression was also positively correlated with epithelial barrier protein genes (CDH1, CLDN1, CLDN4, TJP1, and TJP2) and epithelial genes involved in $\mathrm{T}_{\mathrm{H}} 2$ inflammation (IL33, CCL26, CLC, and ALOX15). Conclusions: Overexpression of $B N C 1$ may be associated with increased expression of $T P 63$, and possibly contribute to the epithelial barrier defects and $\mathrm{T}_{\mathrm{H}} 2$ inflammation in CRSwNP.

๑) 2021 S. Karger AG, Basel

\section{Introduction}

Chronic rhinosinusitis (CRS) is the most common chronic inflammatory disease in the nasal cavity and paranasal sinus mucosa. CRS affects almost $10.9 \%$ of

Yunbo Gao and Jingyun Li contributed equally to the study. Edited by: H.-U. Simon, Bern. karger@karger.com

www.karger.com/iaa

Karger ${ }^{\prime}$ - (c) 2021 S. Karger AG, Base

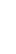

\footnotetext{
Correspondence to:

Yuan Zhang, summer_zhang1211@126.com

Luo Zhang, dr.luozhang@139.com
} 
the population around the world [1]. The main symptoms of the CRS include nasal obstruction, runny nose, headache, and loss of smell, which can seriously affect the quality of life of patients and impose a heavy health and economic burden on society $[2,3]$. According to the presence or absence of nasal polyps (NPs), CRS can be mainly classified into 2 phenotypes; CRS with NPs (CRSwNPs) and CRS without NPs (CRSsNPs) [1]. The main pathological characteristics of CRS are chronic inflammation in the nasal mucosa, including different stages of mucosal thickening up to NP formation [4]. The underlying mechanisms of CRS involve epithelial barrier dysfunction and inflammatory cell infiltration.

The epithelium barrier function depends on the tight junctions and cell adhesion molecules such as E-cadherin, claudin-1/-4, and ZO-1/-2 between the epithelial cells, which play the key role in forming a physical barrier against the environment pathogenic factors. It has been thought that there is usually epithelial barrier dysfunction in CRSwNP. The chronic inflammation in the mucosa of the epithelium can lead to the disturbance of the integral epithelial structure, as detected by decrease in the abovementioned cell-cell adhesion molecules [5], and create a leaky barrier that allows an increased number of inhaled irritants to infiltrate and activate immune cells in the subepithelial space [6]. Moreover, the epithelial cells also secrete epithelial-derived cytokines and chemokines, such as IL33 and eotaxins, which play critical roles in the type- 2 helper $\mathrm{T}\left(\mathrm{T}_{\mathrm{H}} 2\right)$ immune response in the pathogenesis of CRS $[7,8]$. The transcription factor p63, which is considered to be a classic biomarker in the epithelial basal stem cells, may also affect the barrier function, proliferation, and differentiation of the epithelium [5]. The p63 has been shown to regulate the expression and function of the nasal epithelial tight junction proteins [9], and several lines of evidence show that the overexpression of the p63 gene (TP63) contributes to $\mathrm{T}_{\mathrm{H}} 2$ inflammation by regulating the expression of some epithelial genes, including IL33 and ALOX15 [10, 11].

Basonuclin1 (BNC1) located in the q25.2 of chromosome 15 is an epithelial-specific zinc finger transcription factor that participates in the proliferation of the epithelial cells [12] and interacts with RNA polymerase-I and II to activate many promoters of genes [13]. In addition, BNC1 has been found to be a downstream molecule, which is transcriptionally regulated directly by $\mathrm{p} 63$ in the proliferation of the epithelial basal cells [14]. Thus, the current study aimed to explore whether or not BNC1 as an epithelial-specific transcription factor might be in- volved in p63-mediated epithelial dysfunction, including epithelial barrier defects and mucosal inflammation in the development of CRSwNP.

\section{Materials and Methods}

\section{Participants and Design}

A total of 91 patients with CRSwNP and 49 patients with CRSsNP, hospitalized for nasal surgery, were recruited at the Rhinology Department of Beijing Tongren Hospital from January 2018 to October 2019. All subjects fulfilled the criteria of CRS according to EPOS2012 guideline [15]. The diagnosis of CRS was confirmed by trained rhinologists, based on the symptoms, physical examinations, nasal endoscopies, and computed tomographic scans of the sinuses. The patients were excluded if they had used oral or nasal steroids in 4 weeks before recruitment. A total of 28 subjects without any sign of sinusitis and undergoing rhinoseptoplasty for anatomic variations were recruited as the control subjects. The study protocol was approved by the Ethics Committee of Beijing Tongren Hospital, and all the subjects provided written informed consent prior to recruitment. Tissue samples were obtained from NPs of CRSwNP subjects, ethmoid mucosa (EM) of CRSsNP subjects, and inferior turbinate (IT) mucosa of the control subjects during endoscopic sinus surgery.

Prior to endoscopic sinus surgery, nasal brushing specimens were also obtained from NPs, EMs, and ITs of 21 CRSwNP patients, 7 CRSsNP patients, and 6 control subjects, respectively. The nasal brush (Copan, Italy) was rotated 10-15 full turns to acquire the nasal epithelial cells (NECs) in each subject and immediately placed into RNase-free collection tubes. $1 \mathrm{~mL}$ TRIzol ${ }^{\circledR}$ Reagent (Invitrogen, Carlsbad CA, USA) was added to each sample and the samples were stored at $-80^{\circ} \mathrm{C}$ until the RNA extraction.

\section{Tissue Immunochemistry}

Nasal tissue specimens from each patient were processed according to standardized immunocytochemistry procedures. Briefly, the specimens were fixed, dehydrated, and embedded in the wax prior to sectioning. Four-micrometers thick sections were stained with mouse antihuman BNC1 polyclonal antibody (sc-13257, Santa Cruz, CA, USA) at a dilution of 1:100, and 5 random fields with the intact epithelium in each sample were observed by light microscopy ECLIPSE Ni-E (Tokyo, Japan) at $\times 400$ magnification. The BNC1-positive epithelial cells were determined as the mean percentage of the total epithelial cells observed in the 5 fields, using the formula: positively staining cells/total epithelial cells $\times 100 \%$.

\section{Cytospin and Immunofluorescence Staining}

Nasal tissue specimens were incubated in DMEM containing $0.5 \mathrm{mg} / \mathrm{mL}$ dispase II (Sigma) at $4^{\circ} \mathrm{C}$ overnight to obtain single-cell suspensions. At the end of this incubation, $200 \mu \mathrm{L}$ of each cell suspension was loaded into a cytopro ${ }^{\circledR}$ sample chamber (ELITech Group Inc, Logan, UT, USA) and centrifuged at 1,000 rpm for 3 min. The centrifuged cells were dried and then fixed with $4 \%$ paraformaldehyde. For immunofluorescence (IF) staining, the cells were stained using mouse antihuman $\mathrm{BNC1}$ polyclonal antibody (sc-517114, Santa Cruz, Logan, UT, USA 1:100 dilution) and rabbit antihuman p63 monoclonal antibody (ab124762, Abcam, 1:200 dilution), respectively, at $4^{\circ} \mathrm{C}$ overnight. Goat anti-mouse Alexa 
Table 1. Demographic and clinical characteristics of subjects

\begin{tabular}{|c|c|c|c|c|}
\hline & Control $(n=28)$ & CRSsNP $(n=49)$ & CRSwNP $(n=91)$ & $p$ value \\
\hline Age, years, median (IQR) & $36.0(28.0-46.0)$ & $36.0(31.0-51.0)$ & $46.0(32.0-53.0)$ & 0.079 \\
\hline Gender (female/male), $n(\%)$ & $9 / 19(32.1)$ & $20 / 29(40.8)$ & $34 / 57(37.4)$ & 0.816 \\
\hline Duration, years, median (IQR) & - & $2.5(0.5-9.5)$ & $5.0(3.0-10.0)$ & 0.866 \\
\hline Nasal obstruction, median (IQR) & $1.0(0-3.0)$ & $5.5(5.0-8.0)$ & $8.0(2.9-10.0)$ & 0.036 \\
\hline Nasal discharge, median (IQR) & $1.0(0-2.4)$ & $1.0(0-7.0)$ & $1.0(0-6.1)$ & 0.514 \\
\hline Loss of smell, median (IQR) & $0(0-1.0)$ & $2.2(0-7.8)$ & $8.4(6.2-10.0)$ & 0.002 \\
\hline History of nasal surgery, $n(\%)$ & - & $3(6.1)$ & $14(15.4)$ & 0.038 \\
\hline Asthma, $n(\%)$ & 0 & $4(8.2)$ & $23(25.3)$ & 0.002 \\
\hline Atopic, $n(\%)$ & $6(22.2)$ & $15(30.6)$ & $25(27.5)$ & 0.673 \\
\hline Aspirin-exacerbated respiratory, $n(\%)$ & 0 & $1(2.0)$ & $2(2.2)$ & 0.753 \\
\hline Serum total Ige, kU/L, median (IQR) & $58.0(21.6-82.7)$ & $67.1(19.8-282.0)$ & $86.4(41.4-196.3)$ & 0.056 \\
\hline Nasal resistance, median (IQR) & $0.42(0.28-0.55)$ & $0.44(0.23-1.0)$ & $0.58(0.31-0.93)$ & 0.164 \\
\hline
\end{tabular}

CRSwNPs, chronic rhinosinusitis with nasal polyps; CRSsNPs, chronic rhinosinusitis without nasal polyps.

Fluor594 (ZF-0513, 1:100 dilution, ZSGB-BIO, Beijing) and IgGGoat Anti-Rabbit IgG-FITC (ab6717, 1:100 dilution, Abcam, UK) were incubated in the dark at room temperature for $1 \mathrm{~h}$. The samples were then stained for nuclei with $4^{\prime}, 6$-diamidino-2-phenylindole, and the slides were mounted in the mounting medium (ZSGB-BIO, China). Images from the IF slides were obtained using the confocal microscope (Olympus FV12-IXCOV, Japan).

\section{Cell Culture}

NP tissues from 10 patients with CRSwNP obtained at the time of surgery were immediately placed in the cold Hank's balanced salt solution and used for establishing the ex vivo air-liquid interface (ALI) cell cultures, as previously described [16]. Two-day-old ALI cultures were stimulated by the addition of $10 \mathrm{ng} / \mathrm{mL}$ of IL-13 (R\&D Systems) to the culture medium in basolateral compartments of the separate cultures. The cultures were incubated at $37^{\circ} \mathrm{C}$ in $5 \% \mathrm{CO}_{2}$ in air atmosphere for $24 \mathrm{~h}$ and at the end of this incubation; the cells were harvested, and the mRNA was extracted from the cells for assessment of the gene expression.

\section{RNA Extraction, Reverse Transcription, and $q R T-P C R$}

Total RNA in the tissue, nasal brushing samples, and cultured epithelial cells was extracted by the TRIzol ${ }^{\circledR}$ method following the manufacturer's instructions. The quality of the total RNA was assessed with the Nanodrop-2000 (Thermo Fisher Scientific, Waltham, MA, USA). Single-strand cDNA was synthesized with PrimeScript ${ }^{\mathrm{TM}}$ RT Master Mix (TaKaRa Biotechnology, China), and aliquots of cDNA equivalent to $500 \mathrm{ng}$ of the total RNA in each well were used for qRT-PCR (SYBR ${ }^{\circledR}$ Premix Ex Taq, TaKaRa Biotechnology) using an Applied Biosystems ViiA 7 Dx System (Applied Biosystems, Waltham, $\mathrm{MA}, \mathrm{USA}$ ) in $10 \mu \mathrm{L}$ reactions. The primer sequences used are shown in online suppl. Table 1 (for all online suppl. material, see www.karger. com/doi/10.1159/000516810; online repository).

\section{Statistical Analysis}

Statistical analysis was performed using SPSS 23.0 (IBM, New york, NY, USA), and data were presented as median (interquartile range). The $\chi^{2}$ test was used to analyze the classified data. The Mann-Whitney U test was used to analyze the differences between the 2 groups. Differences among the 3 groups were analyzed using the Kruskal-Wallis test. Cross-correlation was calculated and expressed by Spearman's rank correlation coefficient. A $p$ value $<0.05$ was considered to be statistically significant.

\section{Results}

\section{Patient Demographics and Clinical Characteristics}

The demographic and clinical characteristics of the subjects are shown in Table 1 . The age and gender of subjects in control, CRSsNP, and CRSwNP groups were well matched $(p>0.05)$. The patients in CRSwNP group had significantly more serious symptoms of nasal obstruction $(p=0.036)$ and loss of smell $(p=0.002)$, as well as a significantly higher rate of comorbid asthma $(p=0.002)$ and history of nasal surgery $(p=0.038)$ than CRSsNP and control subjects (Table 1). However, the number of subjects with a history of aspirin-exacerbated respiratory disease, the baseline serum total IgE, and nasal resistance were all comparable among the 3 study groups $(p>0.05)$.

\section{BNC1 Expression Is Elevated in NP Tissues from}

Patients with CRSwNP and Positively Associated with TP63 Expression

We first observed that $B N C 1$ mRNA was significantly increased in NP tissues from patients with CRSwNP compared with EM tissues from patients with CRSsNP (1.96fold, $p=0.0003$ ) and IT tissues from control subjects (2.40-fold, $p<0.0001)$ (Fig. 1a). Consistently, the gene 


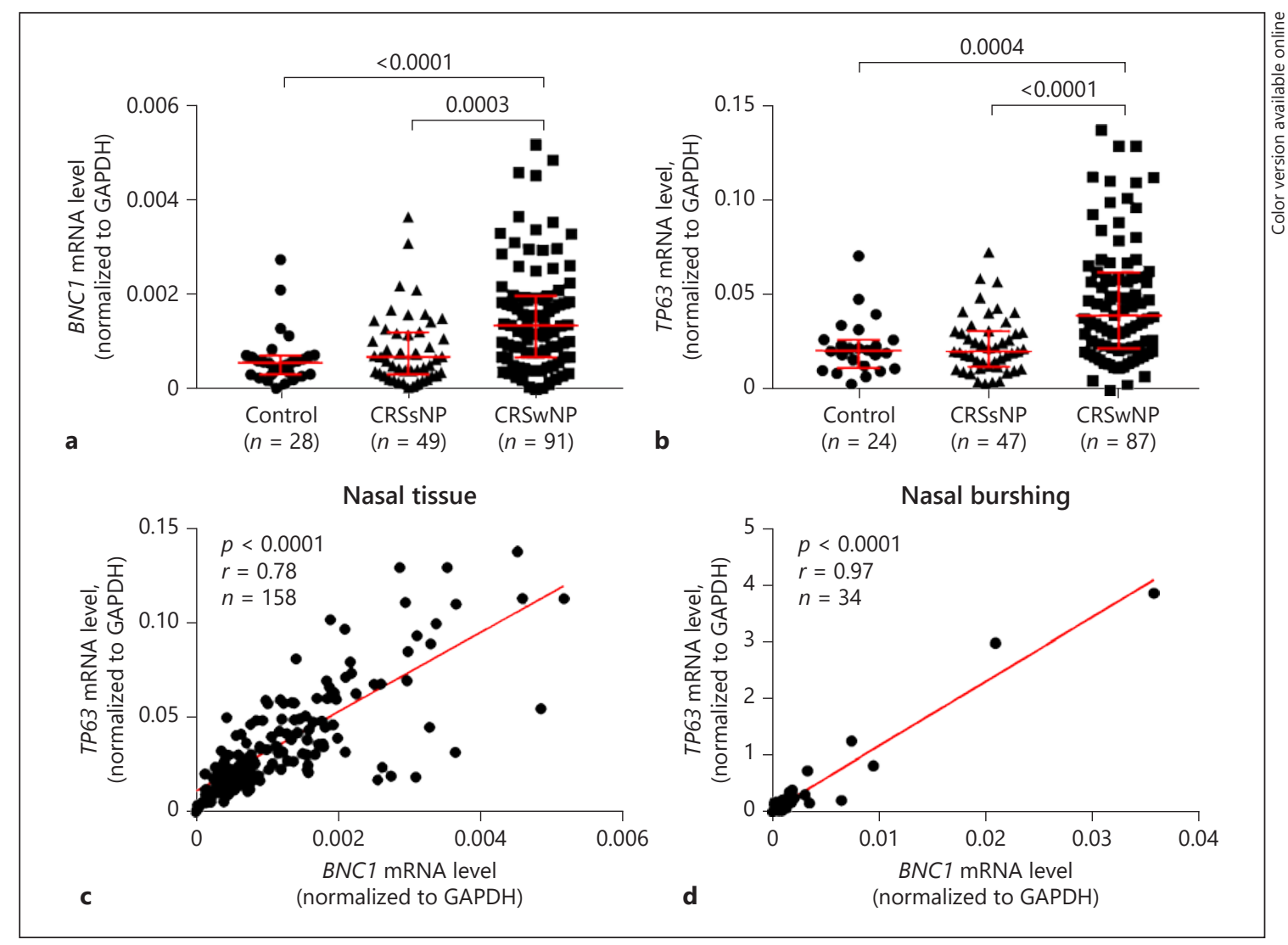

Fig. 1. BNC1 expression is elevated in NP tissues from patients with CRSwNP and positively associated with TP63 expression. Quantitative determination of mRNA by median and interquarter of realtime PCR for BNC1 (a) and P63 (b) in tissues from CRSwNP, CRSsNP, and control subjects. The correlation coefficient was calculated between BNC1 and TP63 mRNA expression levels in the tissues (c) and nasal brushings (d), respectively, which included samples from CRSwNP, CRSsNP to control groups. BNC1, basonuclin1; NP, nasal polyps; CRSwNP, chronic rhinosinusitis with nasal polyps; TP63, tumor protein p63; CRSsNP, chronic rhinosinusitis without nasal polyps. tumor protein p63 (TP63) mRNA in the tissues was also increased in the CRSwNP group compared with CRSsNP (1.87-fold, $p<0.0001)$ and control groups (1.83-fold, $p=$ $0.0004)$ (Fig. 1b).

Assessment of the correlation between the expressions of BNC1 and TP63 mRNA levels in the nasal tissues across the 3 patient groups demonstrated that $B N C 1$ mRNA expression was positively correlated with TP63 mRNA expression ( $r=0.78, p<0.0001)$ (Fig. 1c). Given the dominant expression of TP63 in the tissues from patients with CRSwNP, BNC1 and TP63 mRNA expressions were also detected in brushed NECs from NP, EM, and IT in CRSwNP, CRSsNP, and control groups, respectively. However, BNC1 mRNA expression exhibited a more significant correlation with TP63 mRNA expression in brushed NECs than the mucosal tissues $(r=0.97, p<$ 0.0001 ) (Fig. 1d), although no significant differences were found between the 3 groups ( $p=0.3780$ for $B N C 1$ and $p=0.1242$ for TP63) most likely due to small sample size (Data are not shown).

Furthermore, comparison of the expressions of $B N C 1$ and TP63 mRNA in atopic and nonatopic CRSwNP patients demonstrated that $B N C 1$ expression was significantly higher in atopic CRSwNP patients than in nonallergic CRSwNP patients ( $p=0.0424$, online suppl. Fig. 1a); whereas TP63 expression was not significantly different between the 2 groups. Comparison of $B N C 1$ and TP63 mRNA expression between atopic and nonatopic CRSsNP patients, however, demonstrated no significant difference in the expressions of BNC1 or TP63 between the 2 groups (online suppl. Fig. 1).

Similarly, comparison of expression of $B N C 1$ and TP63 in CRSwNP subjects with first diagnosis and patients with a history of nasal surgery who had relapsed 


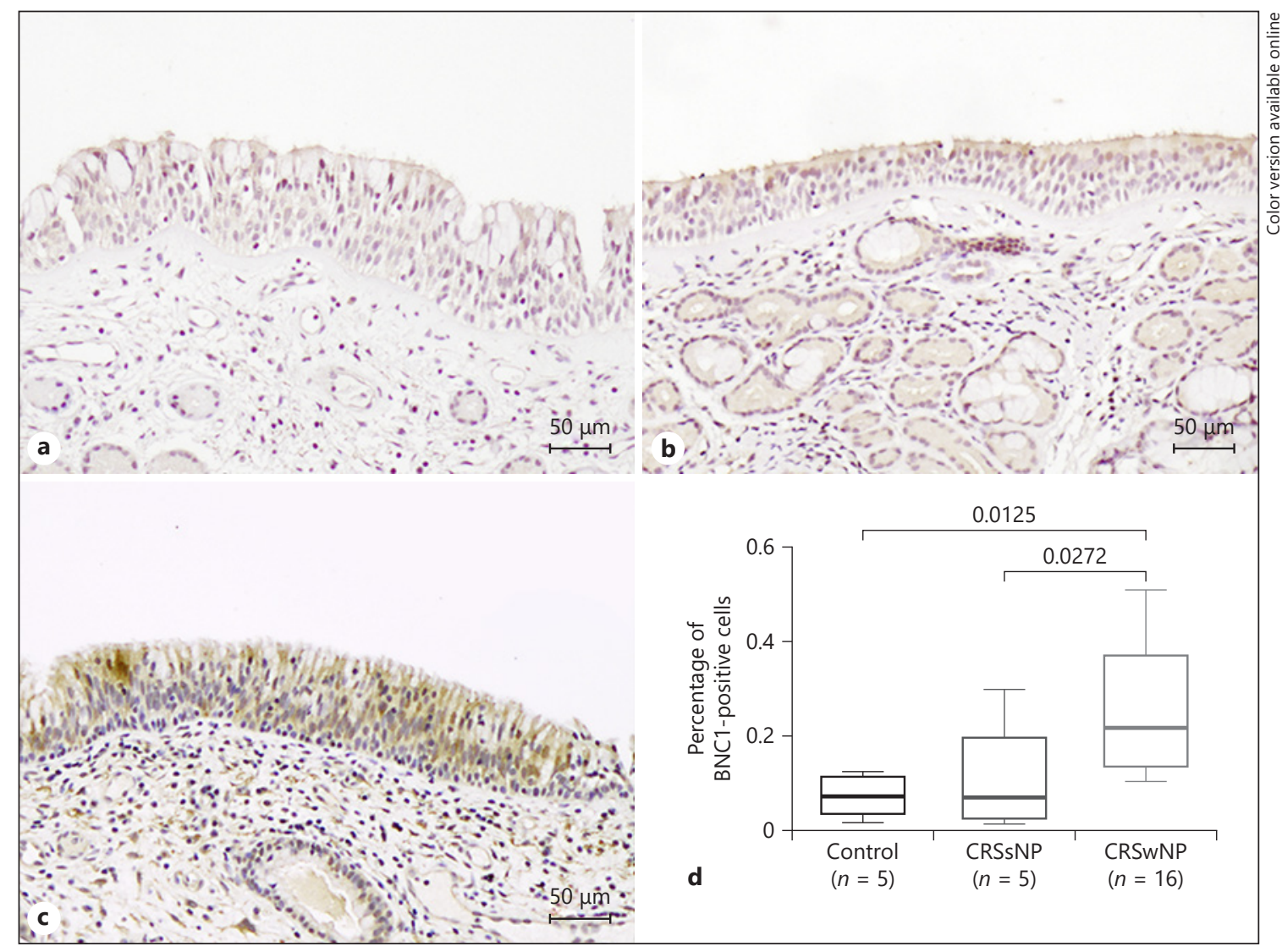

Fig. 2. Images of staining for BNC1 in control (a), CRSsNP (b), CRSwNP (c), and the percentage of BNC1 (+) cell in 3 groups (d). BNC1, basonuclin1; CRSwNP, chronic rhinosinusitis with nasal polyps; CRSsNP, chronic rhinosinusitis without nasal polyps.

indicated that there was no significant difference in the expressions of $B N C 1$ or TP63 between these subgroups ( online suppl. Fig. 2). In contrast, only 3 subjects with a history of nasal surgery had relapsed in the CRSsNP group, and thus, it was not possible to perform a meaningful comparison of the expressions of BNC1 and TP63 in subjects with first diagnosis and those who had relapsed.

BNC1-Positive Staining Is Increased and Co-Localized with $p 63$ in NECs from Patients with CRSwNP

Immunocytochemistry staining was carried out to examine the distribution of $\mathrm{BNC1}$ in the turbinate and polyps tissues. The staining intensity of $\mathrm{BNCl}$ and the percentage of BNC1-positive epithelial cells were significantly increased in the NP epithelial cells from patients with CRSwNP compared with those seen in EM from patients with CRSsNP $(p=0.0275)$ and IT from the control subjects $(p=0.0125)$ (Fig. 2). Cytospin slides of the epithelial cells of NP tissues subjected to double IF staining with $\mathrm{BNC1}$ and p63 demonstrated co-localization of $\mathrm{BNC1}$ and p63 by confocal analysis (Fig. 3 ).

BNC1 Expression Positively Correlates with Epithelial Barrier Genes and Epithelial-Expressed $T_{H} 2$ Inflammatory Genes

Analysis of the epithelial barrier molecules-related genes CDH1, CLDN1, CLDN4, TJP1, and TJP2 demonstrated that these were all expressed in the nasal tissue of the control subjects and CRSsNP and CRSwNP patients (Fig. 4a, d, g, j, m); however, the expression of only CLDN1 was significantly increased in the NP tissues from patients with CRSwNP compared with EM from the patients with CRSsNP $(p=0.0023)$ and IT from the control subjects $(p<0.0001)$ (Fig. 4d).

We further analyzed the expression of the epithelial barrier-related genes in CRSwNP patients classified as expressing high or low levels of $B N C 1$, based on a cutoff 


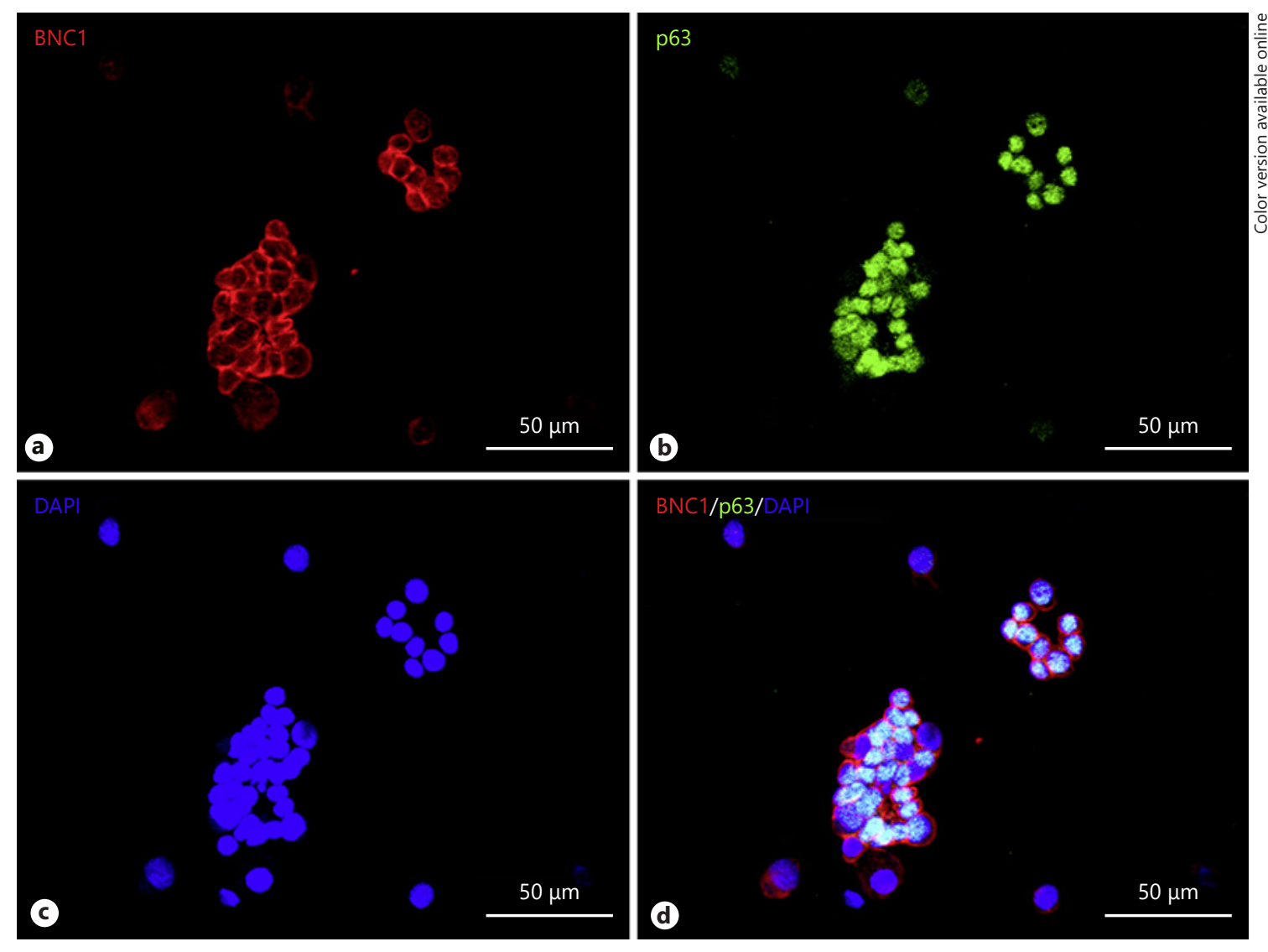

Fig. 3. Fluorescence immunostaining with anti-BNC1 and anti-P63 antibodies of the nasal cells from a CRSwNP subject BNC1 (a), p63 (b), DAPI (c), and double-stained with BNC1 and p63 (d). BNC1, basonuclin1; NP, nasal polyps; CRSwNP, chronic rhinosinusitis with nasal polyps; DAPI, 4',6-diamidino-2-phenylindole.

value of $>90$ th percentile of the $B N C 1$ expression in the control tissue $\left(90\right.$ th percentile $\left.=9.33 \times 10^{-4}\right)$ as being $B N C 1$-high $(B N C 1-\mathrm{H})$ expression and a value below this as being $B N C 1$-low (BNC1-L) expression. This analysis demonstrated that the epithelial barrier-related genes CDH1, CLDN1, CLDN4, TJP1, and TJP2 were all significantly upregulated in the NP tissues for $B N C 1-\mathrm{H}$ CRSwNP subgroup compared to BNC1-L subgroup (Fig. $4 \mathrm{~b}, \mathrm{e}, \mathrm{h}, \mathrm{k}, \mathrm{n}$ ). Moreover, the expression of $B N C 1$ was found to be positively correlated with the expression of all these epithelial barrier genes in CRSwNP patients (Fig. 4c, f, i, l, o).

Analysis of the epithelium-expressed genes related to the inflammatory response in CRSwNP, including $\mathrm{T}_{\mathrm{H}} 2$ related genes (IL33, CLC, CCL26, and ALOX15) and other non- $\mathrm{T}_{\mathrm{H}} 2$ inflammatory genes (IL1B, IL8, IL6, CCL5, and CSF2). The $\mathrm{T}_{\mathrm{H}} 2$-related genes, apart from IL33 (Fig. 5a), CLC, CCL26, and ALOX15 were significantly increased in CRSwNP than in CRSsNP and control sub- jects (Fig. 5d, g, j). Moreover, in CRSwNP patients, apart from IL33 (Fig. 5b), CLC, CCL26, and ALOX15 were significantly increased in $B N C 1$-H CRSwNP subgroup compared to BNC1-L subgroup (Fig. 5b, e, h, k) and also strongly correlated with the expression of BNC1 gene (Fig. 5c, f, i, l). However, no significant differences were found in the other epithelium-expressed inflammation cytokines, including IL1B, IL8, IL6, CCL5, and CSF2 (online suppl. Fig. 3).

Assessment of expression of IL13, which has been shown to be the main effector of the $\mathrm{T}_{\mathrm{H}} 2$ inflammation in $\mathrm{NP}$ and participate in the regulation of the epithelial barrier [17], demonstrated that the expression of IL13 gene was significantly higher in CRSwNP subjects than in CRSsNP and control subjects (Fig. 6a). Furthermore, the expression of IL13 gene was also significantly increased in BNC1-H CRSwNP subgroup compared to BNC1-L CRSwNP subgroup (Fig. 6b) and positively correlated with $B N C 1$ expression (Fig. 6c). 


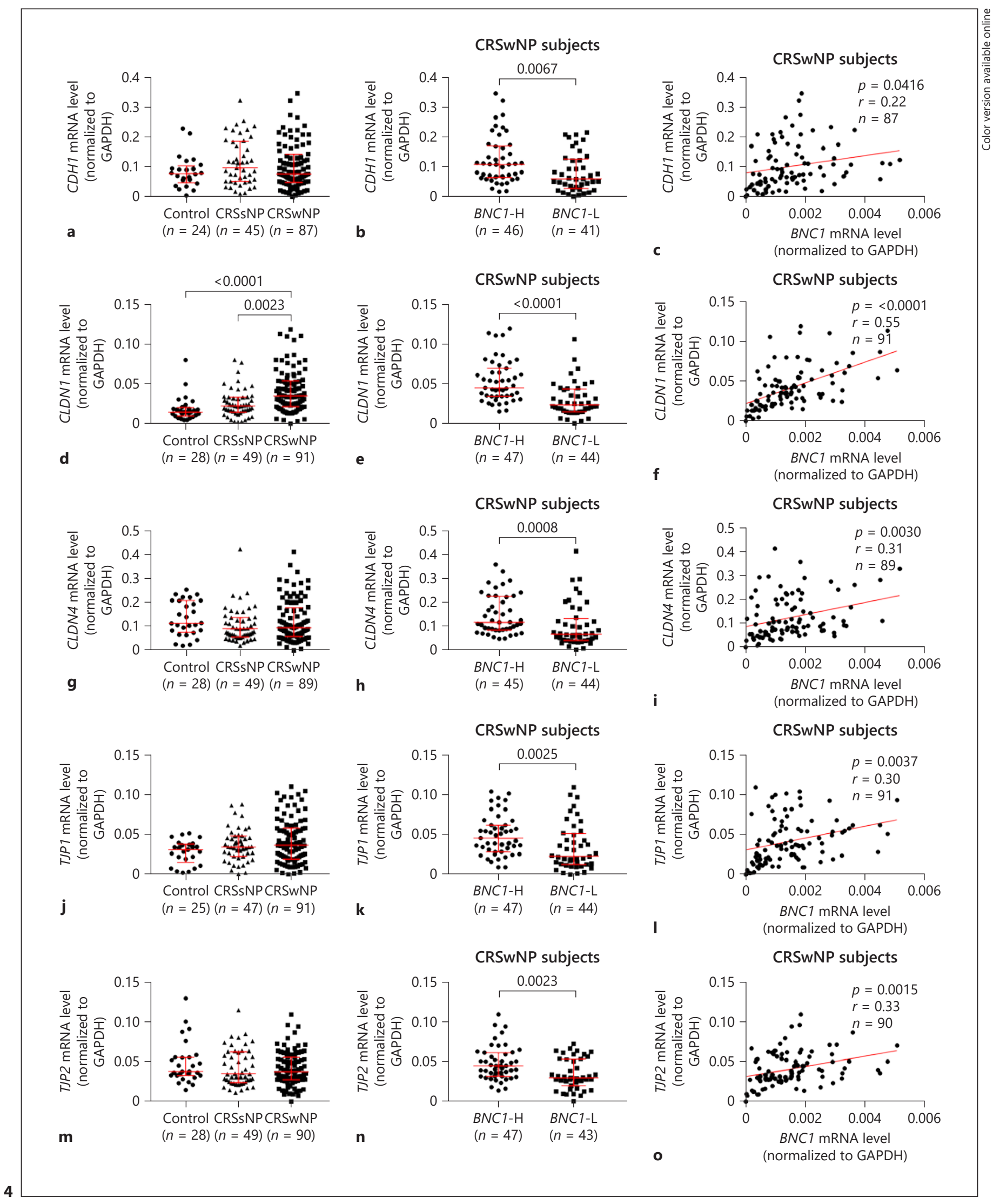

(For legend see next page.) 
Primary ALI-cultured NECs from NP tissues $(n=10)$ treated with IL-13 $(10 \mathrm{ng} / \mathrm{mL})$ for $24 \mathrm{~h}$ that IL-13 did not alter the expression of BNC1 (Fig. 6d) but significantly increased the expression of TP63 (Fig. 6e). However, there was a strong correlation between BNC1 and TP63 mRNA expressions ( $r=0.77, p=0.0126)$ (Fig. 6f).

\section{Discussion}

In this study, we have for the first time demonstrated that the epithelial transcription factor $\mathrm{BNC1}$ may play an important role in the airway epithelium of NPs. We found that the expression of $B N C 1$ was significantly enhanced in CRSwNP subjects, and there was a strong positive correlation with TP63 gene expression. Furthermore, BNC1 was also significantly associated with the expression of epithelial barrier function molecules and $\mathrm{T}_{\mathrm{H}} 2$ inflammatory biomarkers, indicating a possible underlying role in the pathogenesis of CRSwNP.

BNC1 was first discovered in the epithelial stratum corneum [12] and was considered mainly to be involved in the terminal differentiation of keratinocytes [18], corneal epithelial cell damage repair [19], and carcinogenesis of the squamous epithelial cells [20]. As a transcription factor, $\mathrm{BNC1}$ is important for epithelial function by regulating a wide range of genes, which mainly include cell-cell junction, intracellular transport, and other related physiological functions [21]. In hyperplasia in the basal cell and squamous cell carcinoma, the level of $\mathrm{BNC} 1$ has also been found to be elevated [22]. Furthermore, BNC1 was detected to be linked to the maintenance of proliferative capacity and prevention of terminal differentiation [18].

While $\mathrm{BNC1}$, as a transcription factor, is mainly thought to be distributed in the nuclei of the epithelial basal cells [12], the present study has demonstrated that $B N C 1$ was located in the cytoplasm of p63 (+) basal cells. Iuchi and colleagues [23], however, have found that the subcellular localization of $\mathrm{BNC1}$ is more complicated and dependent on the stage of cell growth. The authors demonstrated that in the cultured keratinocytes, BNC1 was mostly located to the cell's nucleus when the cells were in a state of rapid growth and predominantly located in cy-

Fig. 4. Quantitative determination of mRNA by real-time RT-PCR for $B N C 1$ and epithelial barrier-related genes: $C D H 1$ (a), CLDN1 (d), CLDN4 ( $\mathbf{g}), T J P 1(\mathbf{j})$, and TJP2 (m) in the tissues from knockdown, and CRSwNP subjects. The difference between BNC1-H and BNC1-L) in CRSwNP group is shown in (b, e, $\mathbf{h}, \mathbf{k}, \mathbf{n})$. Rela-

Upregulation of Basonuclin1 in Chronic

Rhinosinusitis with Nasal Polyps toplasm during the poor cell growth. This suggests that different states of the keratinocyte require greater or lesser activity of BNC1, and the subcellular location of the protein is probably related to the magnitude of its action on the cells. The change in localization of $\mathrm{BNC1}$ is believed to be due to the phosphorylation state of the protein [24], and activation of BNC1 by phosphorylation has been shown to have a transcriptional regulatory function, which can regulate $\mathrm{BNC1}$ target genes related to the epithelial cell proliferation [22]. Indeed, it has been speculated that in the damaged epithelium, BNC1 in the basal cells at the damaged edge is important in initiating the epithelial cells at the damaged edge to migrate and start re-epithelialization [25]. In CRSwNP subjects, although the number of p63-positive basal cells in the epithelium of NPs has been shown to be significantly increased compared to the epithelium of healthy controls, the percentage of normally proliferating p63 (+)/Ki67(+) basal cells is significantly lower than the control group, which results in the development of multiple layers of basal cells in the aberrant remodeled epithelium in the NPs [26]. In view of these findings, we speculate that the distribution of $\mathrm{BNC1}$ in the cytoplasm of CRSwNP noted in the present study was probably related to a decrease in the normal proliferation of basal cells.

The transcription factor p63 is considered as a classic biomarker in the epithelial basal cells and may affect the barrier function, proliferation, and differentiation of the epithelium and is related to the cause of airway mucosal inflammation [27]. Some studies found that p63-positive basal cells were significantly increased in CRS [28] and NPs [26], while the expression of the tight junctions and adhesion molecules between the epithelial cells were downregulated $[9,29]$. In addition, the higher expression of p63 was considered to be associated with postoperative recurrence of NPs [30]. Although the expression of p63 is related to a variety of biological functions in airway epithelium, a few downstream pathways regulated by $\mathrm{p} 63$ have been found, such as AP-1 [31], and GATA-6 [32], and the downstream molecular mechanisms related to 63 are still unclear. In this study, we found that BNC1 and p63 were highly correlated in terms of the level of gene expression and cell localiza-

tionship between mRNA levels of $B N C 1$ with each gene in CRSwNP subjects is shown in (c, $\mathbf{f}, \mathbf{i}, \mathbf{I}, \mathbf{o})$. BNC1, basonuclin1; CRSwNP, chronic rhinosinusitis with nasal polyps; CRSsNP, chronic rhinosinusitis without nasal polyps; $B N C 1-\mathrm{H}$, high level of $B N C 1 ; B N C 1$ $\mathrm{L}$, low level of BNC1. 


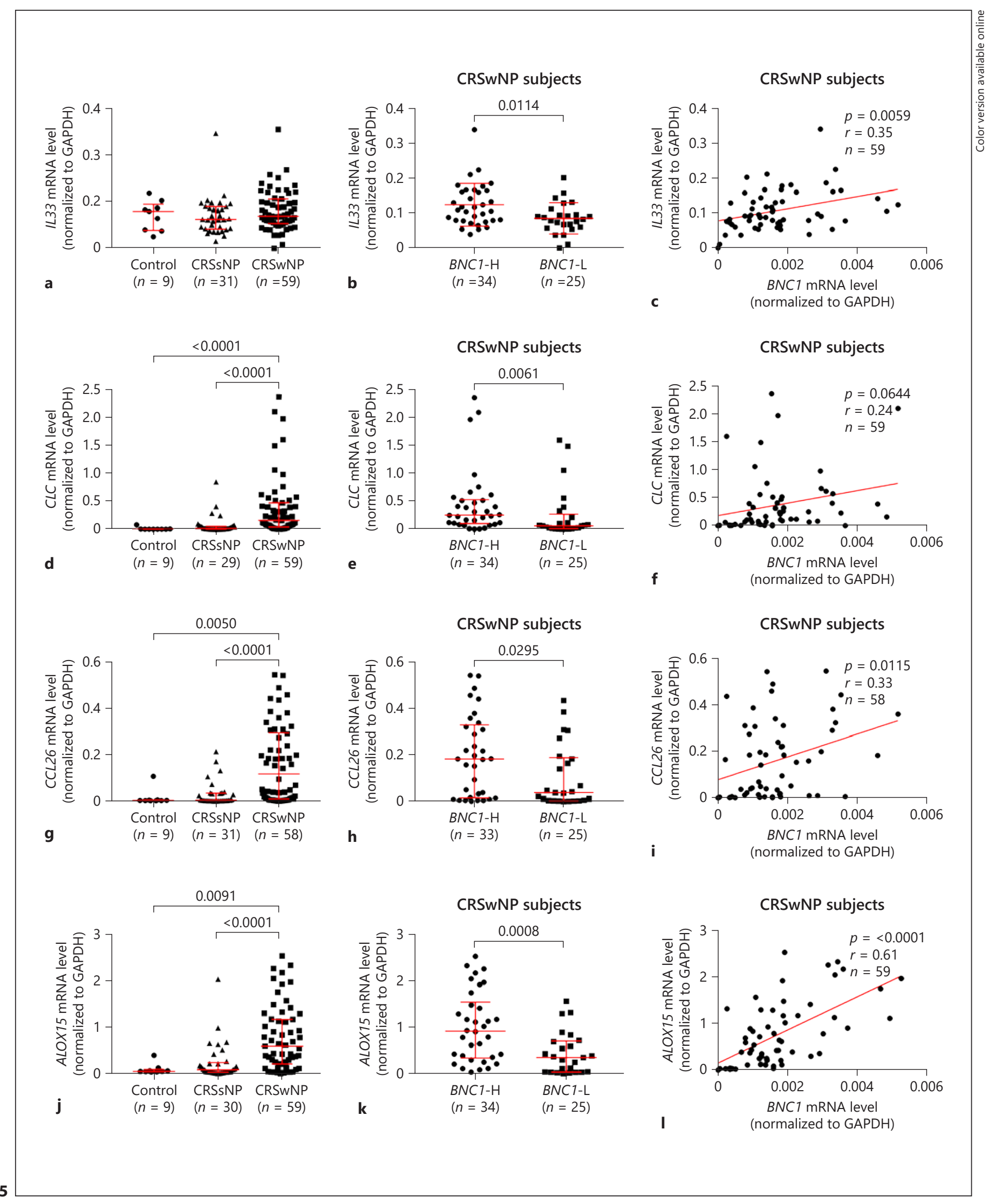

(For legend see next page.) 
tion. Consistent with our finding, Boldrup et al. [14] found that p63 could directly bind to the promoter region of $B N C 1$ gene and induce the expression of $B N C 1$ mRNA. Therefore, we speculate that BNC1 might be a downstream molecular regulator in p63 signaling pathway and may play a role in the mechanism underlying the development of CRSwNP.

The defective epithelial barrier function has been considered to potentially be involved in pathogenesis of different airway diseases, including allergic rhinitis [33], asthma [34], and CRS [35]. The tight junction proteins such as ZO-1 and claudin-1 have also been shown to be significantly lower in CRSwNP patients than in the control subjects [36]. In this study, although no difference was detected in the mRNA levels of CDH1, CLDN1,
CLDN4, TJP1, and TJP2 in CRSwNP patients compared with CRSsNP patients or control subjects, a significant increase was observed specifically in subgroup of patients expressing high levels of BNC1. Zhang et al. [19] found that knockdown $B N C 1$ gene resulted in a downregulation of $C D H 1$ mRNA level in the mouse corneal epithelium. In breast cancer, knocking down the $B N C 1$ gene can increase the protein level of E-cadherin induced by TGF- $\beta 1$, but the mRNA expression is suppressed [37]. These results suggested that there might be a potentially positive regulation of $\mathrm{CDH} 1$ expression by $\mathrm{BNC1}$ gene. In accordance with our findings, Jiao et al. [6] have also found that the mRNA expression of CLDN1 was significantly higher in CRSwNP than in control subjects. It is possible that the increased mRNA levels of the tight junctions and adhe-

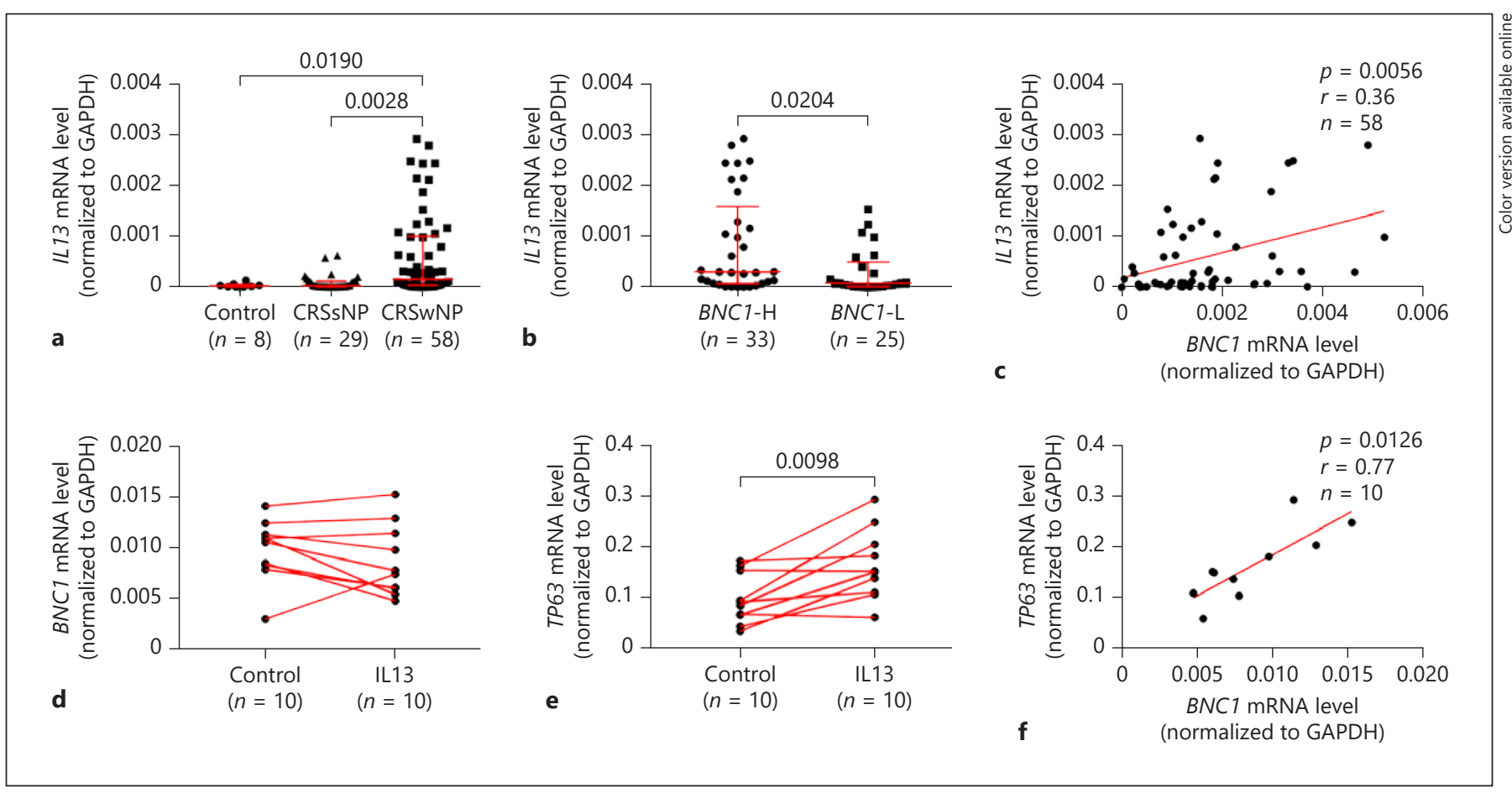

Fig. 6. Quantitative determination of mRNA by real-time PCR for IL13: in the tissues from control, CRSsNP, and CRSwNP subjects (a), in BNC1-H) and BNC1-L in CRSwNP group (b), Relationship between mRNA levels of BNC1 with IL13 gene in CRSwNP subjects (c). After IL13 stimulation, BNC1 (d) and TP63 (e) gene expression changes in ALI-cultured epithelial cells in $24 \mathrm{~h}$. f The cor- relation between mRNA levels of $B N C 1$ with $I L 13$ gene in cultured epithelial cell after IL13 stimulation. BNC1, basonuclin1; CRSwNP, chronic rhinosinusitis with nasal polyps; CRSsNP, chronic rhinosinusitis without nasal polyps; BNC1-H, high level of BNC1; BNC1$\mathrm{L}$, low level of $B N C$; TP63, tumor protein p63; ALI, air-liquid interface.
Fig. 5. Quantitative determination of mRNA by real-time PCR for $B N C 1$ and $\mathrm{T}_{\mathrm{H}} 2$ inflammation-related genes: IL33 (a), CCL26 (d), $C L C(\mathbf{g}), A L O X 15(\mathbf{j})$, and in tissues from control, CRSsNP, and CRSwNP subjects. The difference between BNC1-H and BNC1-L in CRSwNP group is shown in (b, e, $\mathbf{h}, \mathbf{k})$. Relationship between
mRNA levels of BNC1 with each gene in CRSwNP subjects is shown in $(\mathbf{c}, \mathbf{f}, \mathbf{i}, \mathbf{I})$. BNC1, basonuclin 1; CRSwNP, chronic rhinosinusitis with nasal polyps; CRSsNP, chronic rhinosinusitis without nasal polyps; $B N C 1-\mathrm{H}$, high level of $B N C 1$; $B N C 1-\mathrm{L}$, low level of BNC1. 
sion molecules in CRSwNP may be a compensatory correction to the decline in the protein levels, and $\mathrm{BNC1}$ may play a regulatory role in this regard. The effect of BNC1 on the levels of tight junction proteins, however, needs to be further investigated in the future.

Furthermore, our results suggest that there may be an association between $B N C 1$ gene and epithelial-expressed genes, such as IL33, CCL26, CLC, and ALOX15, which were involved in $\mathrm{T}_{\mathrm{H}} 2$ inflammation and upregulated in CRSwNP. Although there is a lack of evidence on the role of $\mathrm{BNC} 1$ in $\mathrm{T}_{\mathrm{H}} 2$ inflammation, it has been shown that $\mathrm{p} 63$ can promote type- 2 inflammations. Rizzo et al. [11] found that IL33 was a p63 target gene in atopic dermatitis and also plays a key role in the $\mathrm{T}_{\mathrm{H}} 2$ inflammatory pathways implicated in NPs. Moreover, ALOX15, which has been shown to be present at mRNA and protein levels in human p63 (+) prostatic intermediate basal cells [38], is regarded as a reliable biomarker for predicting a diagnosis of eosinophilic NPs [10]. These findings indirectly suggest that $\mathrm{BNC1}$ may be a transcription factor involved in epithelial $\mathrm{T}_{\mathrm{H}} 2$ inflammation in the p63 signaling pathway. However, the molecular mechanism needs to be confirmed by in vitro experiments.

Previous studies have confirmed that IL13 participates in the destruction of epithelial barrier and promotes $\mathrm{T}_{\mathrm{H}} 2$ inflammation [39, 40]. Furthermore, p63 has been regarded as a direct effector of IL13-induced $\mathrm{T}_{\mathrm{H}} 2$ inflammation [41]. In the present study, we found that the expression of IL13 was significantly higher in CRSwNP than in CRSsNP and control groups, and there was an association of mRNA expression between IL13 and BNC1 in NPs. Furthermore, although the expression of TP63 increased significantly in IL13-stimulated epithelial cells, the expression of BNC1 was not significantly increased. Thus, we speculate that p63 may play an important role in IL13-mediated $\mathrm{T}_{\mathrm{H}} 2$ inflammation, although the role of $\mathrm{BNC1}$ is presently not clear and needs further investigation. In this regard, the present study is somewhat limited, in that it lacks mechanistic knockdown experiments, which may have demonstrated a direct association between $\mathrm{BNC} 1$ and p63-mediated regulation of the genes involved in the epithelial barrier dysfunction and $\mathrm{T}_{\mathrm{H}} 2$ related inflammation.

In conclusion, our finding that enhanced expression of $B N C 1$ was associated with the genes involved in epithelial barrier function and $\mathrm{T}_{\mathrm{H}} 2$-related inflammation in CRSwNP patients suggests that $B N C 1$ might play an important role in the development of aberrant epithelial barrier function and $\mathrm{T}_{\mathrm{H}} 2$-related inflammation in CRSwNP. Moreover, $B N C 1$ might play a role in p63-me- diated regulation of genes involved in the epithelial barrier junctions and $\mathrm{T}_{\mathrm{H}} 2$-related mediators. However, this needs to be confirmed in further studies, which may provide a better understanding of the pathogenic mechanisms in NPs and other airway diseases.

\section{Acknowledgments}

This work was supported by grants from the National Natural Science Foundation of China (81570895), the program for the Changjiang Scholars and Innovative Research Team (IRT13082), National Natural Science Foundation of China (81630023, 81970849 and 82071022), Beijing Municipal Administration of Hospitals' Mission Plan (SML20150203), Beijing Municipal Administration of Hospitals' Dengfeng plan (DFL20190202), Beijing Municipal Science and Technology Project (Z181100001618002), Beijing Talents Foundation (2018000021223ZK14), and the Public Welfare Development and Reform Pilot Project (2019-10).

\section{Statement of Ethics}

The study protocol was approved by the Ethics Committee of Beijing Tongren Hospital (TRECKY_20150216), and all the subjects provided written informed consent prior to recruitment.

\section{Conflict of Interest Statement}

The author(s) declared no potential conflicts of interest with respect to the research, authorship, and/or publication of this article.

\section{Author Contributions}

Y.B.G. wrote the manuscript. Y.B.G., J.Y.L., and Y.Z. analyzed the data. Y.B.G., J.Y.L., Y.Z. C.S.W, and L.Z. designed the study and revised the manuscript. Y.B.G. and J.Y.L. tested the specimens and collected the clinical data. J.J. cultured the epithelial cell, and Y.L. finished immunochemistry and IF staining.

\section{Availability of Data and Material}

The data that support the findings of this study are available on request from the corresponding author. The data are not publicly available due to privacy or ethical restrictions.
Gao/Li/Jiao/Li/Wang/Zhang/Zhang 


\section{References}

1 Fokkens WJ, Lund VJ, Hopkins C, Hellings PW, Kern R, Reitsma S, et al. European position paper on rhinosinusitis and nasal polyps 2020. Rhinology. 2020;58(Suppl S29):1-464.

2 Chen S, Zhou A, Emmanuel B, Garcia D, Rosta E. Systematic literature review of humanistic and economic burdens of chronic rhinosinusitis with nasal polyposis. Curr Med Res Opin. 2020;36:1913.

3 Lourijsen ES, Fokkens WJ, Reitsma S. Direct and indirect costs of adult patients with chronic rhinosinusitis with nasal polyps. Rhinology. 2020;58(3):213-7.

4 Jiang N, Kern RC, Altman KW. Histopathological evaluation of chronic rhinosinusitis: a critical review. Am J Rhinol Allergy. 2013; 27(5):396-402.

5 Jiao J, Wang C, Zhang L. Epithelial physical barrier defects in chronic rhinosinusitis. Expert Rev Clin Immunol. 2019;15(6):679-88.

6 Jiao J, Wang M, Duan S, Meng Y, Meng N, Li $\mathrm{Y}$, et al. Transforming growth factor- $\beta 1$ decreases epithelial tight junction integrity in chronic rhinosinusitis with nasal polyps. J Allergy Clin Immunol. 2018;141(3):1160-e9.

7 Hristova M, Habibovic A, Veith C, JanssenHeininger YM, Dixon AE, Geiszt M, et al. Airway epithelial dual oxidase 1 mediates allergen-induced IL-33 secretion and activation of type 2 immune responses. J Allergy Clin Immunol. 2016;137(5):1545-e11.

8 Dogan M, Sahin M, Yenisey C. Increased TSLP, IL-33, IL-25, IL-19, IL 21 and amphiregulin (AREG) levels in chronic rhinosinusitis with nasal polyp. Eur Arch Otorhinolaryngol. 2019;276(6):1685-91.

9 Kaneko Y, Kohno T, Kakuki T, Takano KI, Ogasawara N, Miyata R, et al. The role of transcriptional factor p63 in regulation of epithelial barrier and ciliogenesis of human nasal epithelial cells. Sci Rep. 2017;7(1):10935.

10 Liang Z, Yan B, Liu C, Tan R, Wang C, Zhang L. Predictive significance of arachidonate 15-lipoxygenase for eosinophilic chronic rhinosinusitis with nasal polyps. Allergy Asthma Clin Immunol. 2020;16:82.

11 Rizzo JM, Oyelakin A, Min S, Smalley K, Bard J, Luo W, et al. $\triangle$ Np63 regulates IL-33 and IL31 signaling in atopic dermatitis. Cell Death Differ. 2016;23(6): 1073-85.

12 Tseng H, Green H. Basonuclin: a keratinocyte protein with multiple paired zinc fingers. Proc Natl Acad Sci USA. 1992;89(21):103115.

13 Tian Q, Kopf GS, Brown RS, Tseng H. Function of basonuclin in increasing transcription of the ribosomal RNA genes during mouse oogenesis. Development. 2001;128(3):407-16.

14 Boldrup L, Coates PJ, Laurell G, Nylander K. p63 Transcriptionally regulates $\mathrm{BNC1}$, a Pol I and Pol II transcription factor that regulates ribosomal biogenesis and epithelial differentiation. Eur J Cancer. 2012;48(9):1401-6.

15 Fokkens WJ, Lund VJ, Mullol J, Bachert C, Alobid I, Baroody F, et al. EPOS 2012: Euro- pean position paper on rhinosinusitis and nasal polyps 2012. A summary for otorhinolaryngologists. Rhinology. 2012;50(1):1-12.

16 Jiao J, Duan S, Meng N, Li Y, Fan E, Zhang L. Role of IFN- $\gamma$, IL-13, and IL-17 on mucociliary differentiation of nasal epithelial cells in chronic rhinosinusitis with nasal polyps. Clin Exp Allergy. 2016;46(3):449-60.

17 Huang ZQ, Liu J, Ong HH, Yuan T, Zhou XM, Wang J, et al. Interleukin-13 alters tight junction proteins expression thereby compromising barrier function and dampens rhinovirus induced immune responses in nasal epithelium. Front Cell Dev Biol. 2020;8:572749.

18 Tseng H, Green H. Association of basonuclin with ability of keratinocytes to multiply and with absence of terminal differentiation. J Cell Biol. 1994;126(2):495-506.

19 Zhang X, Tseng H. Basonuclin-null mutation impairs homeostasis and wound repair in mouse corneal epithelium. PLoS One. 2007; 2(10):e1087.

20 García-Díez I, Hernández-Muñoz I, Hernández-Ruiz E, Nonell L, Puigdecanet E, BódaloTorruella M, et al. Transcriptome and cytogenetic profiling analysis of matched in situ/invasive cutaneous squamous cell carcinomas from immunocompetent patients. Genes Chromosomes Cancer. 2019;58(3):164-74.

21 Wang J, Zhang S, Schultz RM, Tseng H. Search for basonuclin target genes. Biochem Biophys Res Commun. 2006;348(4):1261-71.

22 Tseng $\mathrm{H}$. Basonuclin, a zinc finger protein associated with epithelial expansion and proliferation. Front Biosci. 1998;3:D985-8.

23 Iuchi S, Easley K, Matsuzaki K, Weiner L, O'Connor N, Green H. Alternative subcellular locations of keratinocyte basonuclin. Exp Dermatol. 2000;9(3):178-84.

24 Iuchi S, Green H. Nuclear localization of basonuclin in human keratinocytes and the role of phosphorylation. Proc Natl Acad Sci USA. 1997;94(15):7948-53.

25 Matsuzaki K, Inoue H, Kumagai N. Re-epithelialisation and the possible involvement of the transcription factor, basonuclin. Int Wound J. 2004;1(2):135-40.

26 Zhao L, Li YY, Li CW, Chao SS, Liu J, Nam $\mathrm{HN}$, et al. Increase of poorly proliferated p63 (+) /Ki67 (+) basal cells forming multiple layers in the aberrant remodeled epithelium in nasal polyps. Allergy. 2017;72(6):975-84.

27 Warner SM, Hackett TL, Shaheen F, Hallstrand TS, Kicic A, Stick SM, et al . Transcription factor p63 regulates key genes and wound repair in human airway epithelial basal cells. Am J Respir Cell Mol Biol. 2013;49(6):978-88.

28 Huang H, Tan KS, Zhou S, Yuan T, Liu J, Ong $\mathrm{HH}$, et al. p63 (+) Krt5 (+) basal cells are increased in the squamous metaplastic epithelium of patients with radiation-induced chronic Rhinosinusitis. Radiat Oncol. 2020; 15(1):222.

29 Kojima T, Kohno T, Kubo T, Kaneko Y, Kakuki T, Kakiuchi A, et al. Regulation of claudin-4 via p63 in human epithelial cells. Ann N Y Acad Sci. 2017;1405(1):25-31.

30 Terrinoni A, Palombo R, Pitolli C, Caporali S, De Berardinis R, Ciccarone S, et al. Role of the TAp63 Isoform in Recurrent Nasal Polyps. Folia Biol. 2019;65(4):170-80.

31 Sundqvist A, Vasilaki E, Voytyuk O, Bai Y, Morikawa M, Moustakas A, et al. TGF $\beta$ and EGF signaling orchestrates the AP-1- and p63 transcriptional regulation of breast cancer invasiveness. Oncogene. 2020;39(22):4436-49.

32 Wang H, Liu Z, Li J, Zhao X, Wang Z, Xu H. $\Delta \mathrm{Np} 63$ a mediates proliferation and apoptosis in human gastric cancer cells by the regulation of GATA-6. Neoplasma. 2012;59(4): $416-23$

33 Wang MJ, Kang MX, Huang MZQ, Shen ML, Luo MQ, Li MMY, et al. Protease-activated receptor-2 decreased zonula occlidens- 1 and claudin-1 expression and induced epithelial barrier dysfunction in allergic rhinitis. Am J Rhinol Allergy. 2020

34 Inoue $\mathrm{H}$, Akimoto $\mathrm{K}$, Homma $\mathrm{T}$, Tanaka $\mathrm{A}$, Sagara H. Airway epithelial dysfunction in asthma: relevant to epidermal growth factor receptors and airway epithelial cells, J Clin Med. 2020;9(11):3698.

35 Soyka MB, Wawrzyniak P, Eiwegger T, Holzmann D, Treis A, Wanke K, et al. Defective epithelial barrier in chronic rhinosinusitis: the regulation of tight junctions by IFN- $\gamma$ and IL-4. J Allergy Clin Immunol. 2012;130(5): 1087-96.

36 Li Y, Wang X, Wang R, Bo M, Fan E, Duan S, et al. The expression of epithelial intercellular junctional proteins in the sinonasal tissue of subjects with chronic rhinosinusitis: a histopathologic study. J Otorhinol Relat Spec. 2014;76(2):110-9.

37 Feuerborn A, Mathow D, Srivastava PK, Gretz N, Gröne HJ.Basonuclin-1 modulates epithelial plasticity and TGF- $\beta 1$-induced loss of epithelial cell integrity. Oncogene. 2015; 34(9):1185-95.

38 Bhatia B, Tang S, Yang P, Doll A, Aumüeller G, Newman RA, et al. Cell-autonomous induction of functional tumor suppressor 15-lipoxygenase 2 (15-LOX2) contributes to replicative senescence of human prostate progenitor cells. Oncogene. 2005;24(22):3583-95.

39 Yuan T, Zheng R, Liu J, Kai Sen T, Huang ZQ, Zhou XM, et al. Role of Yes-associated protein in Interleukin-13 induced nasal remodeling of chronic rhinosinusitis with nasal polyps. Allergy. 2020.

40 Liu J, Li YY, Andiappan AK, Yan Y, Tan KS Ong $\mathrm{HH}$, et al. Role of IL-13Ra2 in modulating IL-13-induced MUC5AC and ciliary changes in healthy and CRSwNP mucosa. Allergy. 2018;73(8):1673-85.

41 Brauweiler AM, Leung DYM, Goleva E. The transcription factor p63 is a direct effector of il-4- and IL-13-mediated repression of keratinocyte differentiation. J Invest Dermatol. 2020. 